\title{
InterCriteria analysis of forest fires in the Mediterranean area in 1990-2017
}

\author{
Vassia Atanassova ${ }^{1}$, Peter Vassilev ${ }^{2}$, \\ Veselina Bureva $^{3}$ and Evdokia Sotirova ${ }^{4}$ \\ 1,2 Bioinformatics and Mathematical Modelling Department, \\ Institute of Biophysics and Biomedical Engineering, Bulgarian Academy of Sciences \\ 105 Acad. Georgi Bonchev Str., Sofia 1113, Bulgaria \\ e-mails: vassia.atanassova@gmail.com, peter.vassilev@gmail.com \\ ${ }^{3,4}$ Intelligent Systems Laboratory, Prof. Dr Asen Zlatarov University \\ 1 Prof. Yakimov Blvd, Burgas 8010, Bulgaria \\ e-mails: vbureva@btu.bg, esotirova@btu.bg
}

\begin{abstract}
In the present paper, the novel decision support method of InterCriteria Analysis, based on the concept of intuitionistic fuzzy sets, has been applied to a dataset of the forest fires in the Mediterranean Area in the period between 1990 and 2017 year. The available data from the European Forest Fire Information System (EFFIS) concern the number of fires and the burned area per year in the seven investigated countries Portugal, Spain, France, Italy, Greece, Turkey, with the addition of Bulgaria. The method aims at detecting patterns of correlation, here specifically termed InterCriteria consonance, between the criteria in the dataset. With the application of the proposed method, the coefficients of intuitionistic fuzzy positive consonance are being calculated between the countries' fire regime indicators, and commented accordingly. The results can be informative for the yearly and countrywise trends in the wildfire activity in the Mediterranean Area in support of prediction and prevention, as well as contribute to the research on InterCriteria Analysis.
\end{abstract}

Keywords: Forest fires, Wildfires, InterCriteria Analysis, Intuitionistic fuzzy sets.

2010 Mathematics Subject Classification: 03 E72.

\section{Introduction}

Forest fires are a serious environmental hazard in southern Europe. Most of the total burned area in Europe occurs in Mediterranean regions, causing severe economic and environmental damage, including the loss of ecosystem services such as carbon sequestration and provisioning of raw materials, the loss of lives and an average of about $4500 \mathrm{~km}^{2}$ burned every year. 
Understanding fire regimes is very important for the assessment of the ecological effects of forest fires and for the analysis of trends and shifts in fire occurrence during the recent history and in the inter-annual variability of the fire activity. Such trends likely result from the combined effect of extreme fire weather events, changes in policies and management practices, law enforcements and reporting systems, [13].

\section{Presentation of the input data}

The input data that has been collected for investigation is extracted from the European Forest Fire Information System (EFFIS) and covers the Southern European Mediterranean countries Portugal, Spain, France, Italy and Greece, with the addition of Turkey and the authors' homeland Bulgaria, whose fire regime in the last years is familiar with that of the Mediterranean countries. For each of these seven countries the data about the burned area (in hectares) and number of fires for the period 1990 - 2017. The input data are as listed below in Table 1 and Table 2, [7].

\begin{tabular}{|c|c|c|c|c|c|c|c|}
\hline Year & Portugal & Spain & France & Italy & Greece & Bulgaria & Turkey \\
\hline 1990 & 137252 & 203032 & 72625 & 195319 & 38594 & 315 & 13742 \\
\hline 1991 & 182486 & 260318 & 10130 & 99860 & 13046 & 511 & 8081 \\
\hline 1992 & 57011 & 105277 & 16593 & 105692 & 71410 & 5243 & 12232 \\
\hline 1993 & 49963 & 89267 & 16698 & 203749 & 54049 & 18164 & 15393 \\
\hline 1994 & 77323 & 437635 & 24995 & 136334 & 57908 & 18100 & 38128 \\
\hline 1995 & 169612 & 143484 & 18137 & 48884 & 27202 & 550 & 7676 \\
\hline 1996 & 88867 & 59814 & 11400 & 57988 & 25310 & 906 & 14922 \\
\hline 1997 & 30535 & 98503 & 21581 & 111230 & 52373 & 595 & 6316 \\
\hline 1998 & 158369 & 133643 & 19282 & 155553 & 92901 & 6967 & 6764 \\
\hline 1999 & 70613 & 82217 & 15906 & 71117 & 8289 & 8291 & 5804 \\
\hline 2000 & 159605 & 188586 & 24078 & 114648 & 145033 & 57406 & 26353 \\
\hline 2001 & 111850 & 93297 & 20642 & 76427 & 18221 & 20152 & 7394 \\
\hline 2002 & 124411 & 107464 & 30160 & 40791 & 6013 & 6513 & 8514 \\
\hline 2003 & 425726 & 148172 & 73278 & 91805 & 3517 & 5000 & 6644 \\
\hline 2004 & 129539 & 134193 & 13711 & 60176 & 10267 & 1137 & 4876 \\
\hline 2005 & 338262 & 188697 & 22135 & 47575 & 6437 & 1456 & 2821 \\
\hline 2006 & 75510 & 155345 & 7844 & 39946 & 12661 & 3540 & 7762 \\
\hline 2007 & 31450 & 86122 & 8570 & 227729 & 225734 & 42999 & 11664 \\
\hline 2008 & 17244 & 50322 & 6001 & 66329 & 29152 & 5289 & 29749 \\
\hline 2009 & 87416 & 120094 & 17000 & 73355 & 35342 & 2271 & 4679 \\
\hline 2010 & 133090 & 54770 & 10300 & 46537 & 8967 & 6526 & 3317 \\
\hline 2011 & 73813 & 102161 & 9400 & 72004 & 29144 & 6883 & 3612 \\
\hline 2012 & 110231 & 226125 & 8600 & 130814 & 59924 & 12730 & 10455 \\
\hline 2013 & 152756 & 58985 & 3608 & 29076 & 46676 & 3314 & 11456 \\
\hline 2014 & 19929 & 46721 & 7493 & 36125 & 25846 & 916 & 3117 \\
\hline 2015 & 64443 & 103200 & 11160 & 41511 & 7096 & 4313 & 3219 \\
\hline 2016 & 161522 & 65817 & 16093 & 47926 & 26540 & 6340 & 9156 \\
\hline 2017 & 540630 & 178234 & 26378 & 161987 & 13393 & 4569 & 11993 \\
\hline
\end{tabular}

Table 1. Overview of the burned area reported by the investigated seven countries 


\begin{tabular}{|c|c|c|c|c|c|c|c|}
\hline Year & Portugal & Spain & France & Italy & Greece & Bulgaria & Turkey \\
\hline 1990 & 10745 & 12913 & 5881 & 14477 & 1322 & 76 & 1750 \\
\hline 1991 & 14327 & 13531 & 3888 & 11965 & 858 & 73 & 1481 \\
\hline 1992 & 14954 & 15955 & 4002 & 14641 & 2582 & 602 & 2117 \\
\hline 1993 & 16101 & 14254 & 4769 & 14412 & 2406 & 1196 & 2545 \\
\hline 1994 & 19983 & 19263 & 4618 & 11588 & 1763 & 667 & 3239 \\
\hline 1995 & 34116 & 25827 & 6563 & 7378 & 1438 & 114 & 1770 \\
\hline 1996 & 28626 & 16771 & 6401 & 9093 & 1508 & 246 & 1645 \\
\hline 1997 & 23497 & 22320 & 8005 & 11612 & 2273 & 200 & 1339 \\
\hline 1998 & 34676 & 22446 & 6289 & 9540 & 1842 & 578 & 1932 \\
\hline 1999 & 25477 & 18237 & 4960 & 6932 & 1486 & 320 & 2075 \\
\hline 2000 & 34109 & 24118 & 4603 & 8595 & 2581 & 1710 & 2353 \\
\hline 2001 & 26533 & 19547 & 4309 & 7134 & 2535 & 825 & 2631 \\
\hline 2002 & 26488 & 19929 & 4097 & 4601 & 1141 & 402 & 1471 \\
\hline 2003 & 26195 & 18616 & 7023 & 9697 & 1452 & 452 & 2177 \\
\hline 2004 & 21870 & 21396 & 3775 & 6428 & 1748 & 294 & 1762 \\
\hline 2005 & 35697 & 25492 & 4698 & 7951 & 1544 & 241 & 1530 \\
\hline 2006 & 19929 & 16354 & 4608 & 5634 & 1417 & 393 & 2227 \\
\hline 2007 & 18722 & 10936 & 3364 & 10639 & 1983 & 1479 & 2829 \\
\hline 2008 & 13832 & 11655 & 2781 & 6486 & 1481 & 582 & 2135 \\
\hline 2009 & 26119 & 15643 & 4800 & 5422 & 1063 & 314 & 1793 \\
\hline 2010 & 22026 & 11721 & 3900 & 4884 & 1052 & 222 & 1861 \\
\hline 2011 & 25221 & 16414 & 4500 & 8181 & 1653 & 635 & 1954 \\
\hline 2012 & 21176 & 17503 & 4105 & 8252 & 1559 & 876 & 2450 \\
\hline 2013 & 19291 & 10626 & 2223 & 2936 & 862 & 408 & 3755 \\
\hline 2014 & 7067 & 9771 & 2778 & 3257 & 552 & 151 & 2149 \\
\hline 2015 & 15851 & 11928 & 4440 & 5442 & 510 & 429 & 2150 \\
\hline 2016 & 13261 & 8817 & 4285 & 4793 & 777 & 584 & 3188 \\
\hline 2017 & 21002 & 13793 & 4403 & 7855 & 1083 & 513 & 2411 \\
\hline
\end{tabular}

Table 2. Overview of the number of fires reported by the investigated seven countries

\section{Application of the intercriteria analysis}

Here we are interested in detecting patterns and trends between the investigated countries' fire regimes, specifically the criteria Number of Fires and Burned Area. We are mainly interested in results in the following three directions: dependencies between the burned areas in the different countries, between the number of fires that have occurred in the different countries, as well as between the pairs of criteria Burned Area and Number of Fires per investigated country. The method of InterCriteria Analysis (ICA) is based on intuitionistic fuzzy sets, thus rendering account of the effects of uncertainty. Originally, ICA was been proposed in [2], and various aspects of its theoretical investigation are given in papers [1, 3-6, 12, 15].

For this aim, we use the developed software for InterCriteria Analysis [8-11] (freely available online at: http://intercriteria.net/software) and feed it with the combined data for the 
whole period. The complete resultant table with InterCriteria intuitionistic fuzzy pairs, as divided in membership and non-membership parts, is given on Table 3 (a) and (b).

(a)

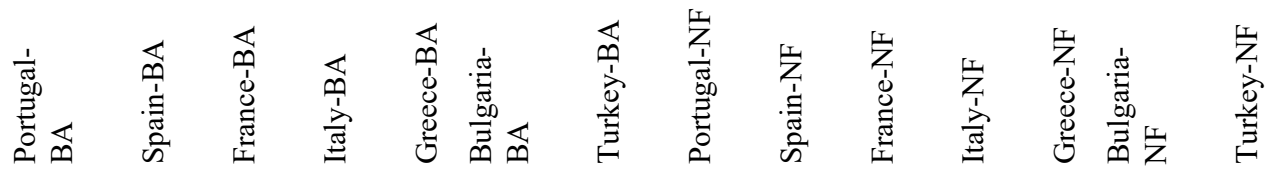

Portugal-BA

Spain-BA

France-BA

Italy-BA

Greece-BA

Bulgaria-BA

Turkey-BA

Portugal-NF

\begin{tabular}{lllllll|lllllll}
1.000 & 0.683 & 0.659 & 0.495 & 0.407 & 0.426 & 0.487 & 0.648 & 0.624 & 0.561 & 0.487 & 0.389 & 0.384 & 0.437
\end{tabular} $\begin{array}{llllllllllllllllll}0.683 & 1.000 & 0.696 & 0.638 & 0.508 & 0.460 & 0.556 & 0.571 & 0.672 & 0.593 & 0.667 & 0.519 & 0.447 & 0.429\end{array}$ \begin{tabular}{llllllll|lllllllll}
0.659 & 0.696 & 1.000 & 0.653 & 0.455 & 0.505 & 0.540 & 0.653 & 0.683 & 0.704 & 0.630 & 0.556 & 0.452 & 0.399 \\
\hline
\end{tabular} $\begin{array}{lllllllllllllllllll}0.495 & 0.638 & 0.653 & 1.000 & 0.712 & 0.616 & 0.675 & 0.487 & 0.537 & 0.587 & 0.807 & 0.693 & 0.606 & 0.534\end{array}$ \begin{tabular}{llllllll|l|lllllll}
0.407 & 0.508 & 0.455 & 0.712 & 1.000 & 0.590 & 0.693 & 0.442 & 0.481 & 0.474 & 0.646 & 0.648 & 0.619 & 0.579
\end{tabular} \begin{tabular}{llllllll|lllllllll}
0.426 & 0.460 & 0.505 & 0.616 & 0.590 & 1.000 & 0.593 & 0.542 & 0.521 & 0.434 & 0.521 & 0.664 & 0.831 & 0.683
\end{tabular} $\begin{array}{lllllllllllllllll}0.487 & 0.556 & 0.540 & 0.675 & 0.693 & 0.593 & 1.000 & 0.418 & 0.474 & 0.471 & 0.646 & 0.585 & 0.624 & 0.590\end{array}$

Spain-NF

France-NF

Italy-NF

Greece-NF

Bulgaria-NF \begin{tabular}{l|llllllllllllllll}
0.648 & 0.571 & 0.653 & 0.487 & 0.442 & 0.542 & 0.418 & 1.000 & 0.810 & 0.664 & 0.492 & 0.579 & 0.439 & 0.368
\end{tabular} \begin{tabular}{lllllll|l|l|l|l|lll}
0.624 & 0.672 & 0.683 & 0.537 & 0.481 & 0.521 & 0.474 & 0.810 & 1.000 & 0.693 & 0.585 & 0.664 & 0.444 & 0.344
\end{tabular} \begin{tabular}{ll|l|lllll|llllllll}
0.561 & 0.593 & 0.704 & 0.587 & 0.474 & 0.434 & 0.471 & 0.664 & 0.693 & 1.000 & 0.646 & 0.542 & 0.376 & 0.349
\end{tabular} \begin{tabular}{llllllll|llllllll}
0.487 & 0.667 & 0.630 & 0.807 & 0.646 & 0.521 & 0.646 & 0.492 & 0.585 & 0.646 & 1.000 & 0.714 & 0.516 & 0.442
\end{tabular} \begin{tabular}{llllllll|llllllll}
0.389 & 0.519 & 0.556 & 0.693 & 0.648 & 0.664 & 0.585 & 0.579 & 0.664 & 0.542 & 0.714 & 1.000 & 0.627 & 0.487
\end{tabular}

Turkey-NF \begin{tabular}{lllll|l|lllllllll}
0.384 & 0.447 & 0.452 & 0.606 & 0.619 & 0.831 & 0.624 & 0.439 & 0.444 & 0.376 & 0.516 & 0.627 & 1.000 & 0.696
\end{tabular} \begin{tabular}{lllllllllllllllll}
0.437 & 0.429 & 0.399 & 0.534 & 0.579 & 0.683 & 0.590 & 0.368 & 0.344 & 0.349 & 0.442 & 0.487 & 0.696 & 1.000 \\
\hline
\end{tabular}

(b)

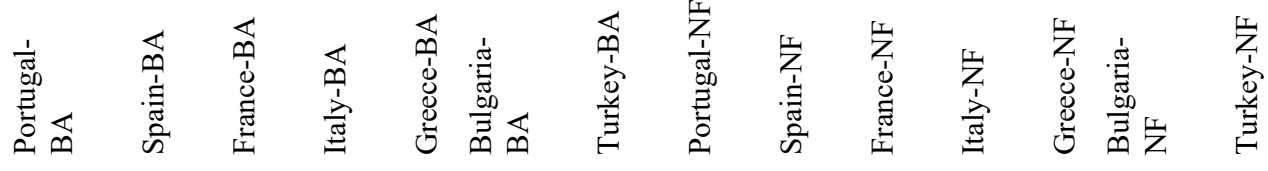

Portugal-BA

Spain-BA

France-BA

Italy-BA

Greece-BA

Bulgaria-BA

Turkey-BA

Portugal-NF

Spain-NF

France-NF

Italy-NF

Greece-NF

Bulgaria-NF

Turkey-NF

\begin{tabular}{|c|c|c|c|c|c|c|c|c|c|c|c|c|c|}
\hline 000 & 0.317 & 0.339 & 0.505 & 0.593 & 0.566 & 0.513 & .347 & 0.370 & 0.415 & 0.508 & 0.556 & 0.529 & 05 \\
\hline 0.317 & 00 & 302 & 62 & 0.492 & 0.532 & 444 & 423 & 0.323 & 0.384 & 0.328 & 0.426 & 0.466 & 0.513 \\
\hline 339 & 2 & 0.000 & 344 & 0.542 & 0.484 & 58 & 39 & 0.310 & 270 & 0.362 & 0.386 & 58 & 0.540 \\
\hline .505 & 362 & 0.344 & 0.000 & 0.288 & 0.376 & 0.325 & 0.508 & 0.458 & 0.389 & 88 & 51 & 307 & 107 \\
\hline 0.593 & 0.492 & 0.542 & 0.288 & 0.000 & 0.402 & 0.307 & 0.553 & 0.513 & 0.503 & 0.349 & 0.296 & 0.294 & 0.362 \\
\hline 0.566 & 0 & 0 & 0 & 0 & 00 & 9 & 14 & 56 & 34 & 66 & 78 & 79 & 51 \\
\hline .513 & 444 & 0.458 & 0.325 & 0.307 & 0.399 & 0.000 & 577 & 0.521 & 0.505 & 0.349 & 0.360 & 38 & 0.352 \\
\hline 34 & 423 & 339 & 0.508 & 0.553 & 0.444 & 0.577 & .000 & 180 & 0.307 & 0.497 & .360 & .468 & ( \\
\hline 0.370 & 323 & 10 & 458 & 513 & 466 & 521 & 30 & 0 & 0.278 & 405 & 75 & 33 & 0.593 \\
\hline 0.415 & 84 & 270 & 0 & 0.50 & 0.534 & 5 & 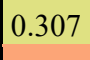 & 0.278 & 000 & 25 & 8 & 3 & 0.574 \\
\hline 3 & . & 62 & 0.188 & 349 & 466 & 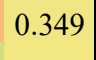 & 497 & 5 & 5 & 0 & 0.225 & 0.392 & (2) \\
\hline 556 & 426 & 386 & 0.25 & 296 & 0.278 & 50 & 360 & 5 & 8 & 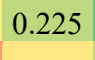 & 00 & 0.235 & 0.405 \\
\hline 0.529 & 0.466 & 0.458 & 0.307 & 0 & 0.079 & 38 & 58 & 163 & 3 & 0 & 0.235 & 0.000 & 0.1 \\
\hline .505 & 0.513 & 0.540 & 0.407 & 0.36 & 0.251 & 0.552 & 0.569 & 0.593 & 0.574 & 0.495 & 0.405 & 0.180 & 0.00 \\
\hline
\end{tabular}

Table 3. Results of the application of the InterCriteria Analysis on the aggregated data from Tables 1 and 2. (a) membership parts, (b) non-membership parts of the IF pairs 
From the upper left quadrants of Table $3(a, b)$ we obtain information about the countrywise relations discovered between the burned areas among all pairs of investigated countries, see Table 4.

\begin{tabular}{|l|l|r|r|r|}
\hline Criterion $\boldsymbol{i}$ & Criterion $\boldsymbol{j}$ & \multicolumn{1}{l|}{$\boldsymbol{\mu}$} & \multicolumn{1}{l|}{$\boldsymbol{\nu}$} & Distance to Truth \\
\hline Italy-BA & Greece-BA & 0.712 & 0.288 & 0.408 \\
\hline Spain-BA & France-BA & 0.698 & 0.302 & 0.427 \\
\hline Greece-BA & Turkey-BA & 0.693 & 0.307 & 0.434 \\
\hline Portugal-BA & Spain-BA & 0.683 & 0.317 & 0.449 \\
\hline Italy-BA & Turkey-BA & 0.675 & 0.325 & 0.460 \\
\hline Portugal-BA & France-BA & 0.661 & 0.339 & 0.479 \\
\hline France-BA & Italy-BA & 0.653 & 0.347 & 0.490 \\
\hline Spain-BA & Italy-BA & 0.638 & 0.362 & 0.513 \\
\hline Italy-BA & Bulgaria-BA & 0.622 & 0.378 & 0.535 \\
\hline Greece-BA & Bulgaria-BA & 0.598 & 0.402 & 0.569 \\
\hline Bulgaria-BA & Turkey-BA & 0.593 & 0.407 & 0.576 \\
\hline Spain-BA & Turkey-BA & 0.556 & 0.444 & 0.629 \\
\hline France-BA & Turkey-BA & 0.540 & 0.460 & 0.651 \\
\hline Spain-BA & Greece-BA & 0.508 & 0.492 & 0.696 \\
\hline France-BA & Bulgaria-BA & 0.508 & 0.492 & 0.696 \\
\hline Portugal-BA & Italy-BA & 0.495 & 0.505 & 0.715 \\
\hline Portugal-BA & Turkey-BA & 0.487 & 0.513 & 0.726 \\
\hline Spain-BA & Bulgaria-BA & 0.460 & 0.540 & 0.763 \\
\hline France-BA & Greece-BA & 0.455 & 0.545 & 0.771 \\
\hline Portugal-BA & Bulgaria-BA & 0.429 & 0.571 & 0.808 \\
\hline Portugal-BA & Greece-BA & 0.407 & 0.593 & 0.838 \\
\hline
\end{tabular}

Table 4. InterCriteria pairs between the burned areas per countries, sorted by their distance to the intuitionistic fuzzy truth $\langle 1,0\rangle$

While not strictly strong positive consonances per [1], we see that the strongest available ones, i.e. those with smallest distance from the intuitionistic fuzzy truth $\langle 1,0\rangle$, are those detected between the neighbouring countries, with the top ranking pairs being Italy-Greece $\langle 0.712,0.288\rangle$, Spain-France $\langle 0.698,0.302\rangle$, Greece-Turkey $\langle 0.693,0.307\rangle$, Portugal-Spain $\langle 0.683,0.317\rangle$. The pairs formed between distantly located countries tend to belong to the dissonance and the negative consonance spectrum, as well as the pairs involving Bulgaria.

Second, from the lower right quadrants of Table $3(a, b)$ we obtain information about the countrywise relations discovered between the numbers of fires registered in between all pairs of investigated countries, see Table 5.

The strongest available InterCriteria pairs again are those detected between the neighbouring countries, with the top ranking pairs being Spain-Portugal $\langle 0.810,0.180\rangle$, Turkey-Bulgaria $\langle 0.696,0.180\rangle$, Greece-Italy $\langle 0.714$, 0.225 $\rangle$, France-Spain $\langle 0.693,0.278\rangle$. The pairs formed between distantly located countries tend to belong to the dissonance and the negative consonance spectrum, as well as the pairs involving Turkey and Bulgaria. 


\begin{tabular}{|l|l|r|r|r|}
\hline Criterion $\boldsymbol{i}$ & Criterion $\boldsymbol{j}$ & $\boldsymbol{\mu}$ & \multicolumn{1}{l|}{$\boldsymbol{N}$} & Distance to Truth \\
\hline Spain-NF & Portugal-NF & 0.810 & 0.180 & 0.262 \\
\hline Turkey-NF & Bulgaria-NF & 0.696 & 0.180 & 0.353 \\
\hline Greece-NF & Italy-NF & 0.714 & 0.225 & 0.364 \\
\hline France-NF & Spain-NF & 0.693 & 0.278 & 0.414 \\
\hline Greece-NF & Spain-NF & 0.664 & 0.275 & 0.434 \\
\hline Bulgaria-NF & Greece-NF & 0.627 & 0.235 & 0.441 \\
\hline France-NF & Portugal-NF & 0.664 & 0.307 & 0.455 \\
\hline Italy-NF & France-NF & 0.646 & 0.325 & 0.481 \\
\hline Greece-NF & Portugal-NF & 0.579 & 0.360 & 0.554 \\
\hline Italy-NF & Spain-NF & 0.585 & 0.405 & 0.580 \\
\hline Greece-NF & France-NF & 0.542 & 0.378 & 0.594 \\
\hline Bulgaria-NF & Italy-NF & 0.516 & 0.392 & 0.623 \\
\hline Turkey-NF & Greece-NF & 0.487 & 0.405 & 0.654 \\
\hline Italy-NF & Portugal-NF & 0.492 & 0.497 & 0.711 \\
\hline Bulgaria-NF & Spain-NF & 0.444 & 0.463 & 0.724 \\
\hline Bulgaria-NF & Portugal-NF & 0.439 & 0.468 & 0.731 \\
\hline Turkey-NF & Italy-NF & 0.442 & 0.495 & 0.746 \\
\hline Bulgaria-NF & France-NF & 0.376 & 0.513 & 0.808 \\
\hline Turkey-NF & Portugal-NF & 0.368 & 0.569 & 0.850 \\
\hline Turkey-NF & France-NF & 0.349 & 0.574 & 0.868 \\
\hline Turkey-NF & Spain-NF & 0.344 & 0.593 & 0.884 \\
\hline
\end{tabular}

Table 5. InterCriteria pairs between the numbers of fires per countries, sorted by their distance to the intuitionistic fuzzy truth $\langle 1,0\rangle$

Finally, in Table 6 and graphically in Figure 1, are presented the results of the application of ICA on the data for the countries' burned areas and numbers of fires, and we are interested in the InterCriteria correlations between each country's number of fires and burned area. From the lower left quadrant, we only collect the results in the seven cells along the main diagonal, as in the other cells while there are computed degrees they are logically inconsistent. The results show that positive InterCriteria consonances are only detected in Bulgaria and Italy, respectively $\langle 0.831,0.079\rangle$ and $\langle 0.807,0.188\rangle$, while France, Greece, Spain, Portugal and Turkey score intuitionistic fuzzy dissonant values.

\begin{tabular}{|l|l|r|r|r|}
\hline & & & \multicolumn{2}{|l|}{ Distance to } \\
Area burned & Number of fires & \multicolumn{1}{|l|}{$\boldsymbol{\mu}$} & \multicolumn{1}{|l|}{$\boldsymbol{N}$} & \multicolumn{2}{l|}{ Truth } \\
\hline Bulgaria & Bulgaria & 0.831 & 0.079 & 0.187 \\
\hline Italy & Italy & 0.807 & 0.188 & 0.269 \\
\hline France & France & 0.704 & 0.270 & 0.401 \\
\hline Greece & Greece & 0.648 & 0.296 & 0.460 \\
\hline Spain & Spain & 0.672 & 0.323 & 0.460 \\
\hline Portugal & Portugal & 0.648 & 0.347 & 0.494 \\
\hline Turkey & Turkey & 0.590 & 0.352 & 0.540 \\
\hline
\end{tabular}

Table 6. InterCriteria pairs between the numbers of fires and burned areas in the investigated countries, sorted by their distance to the intuitionistic fuzzy truth $\langle 1,0\rangle$ 


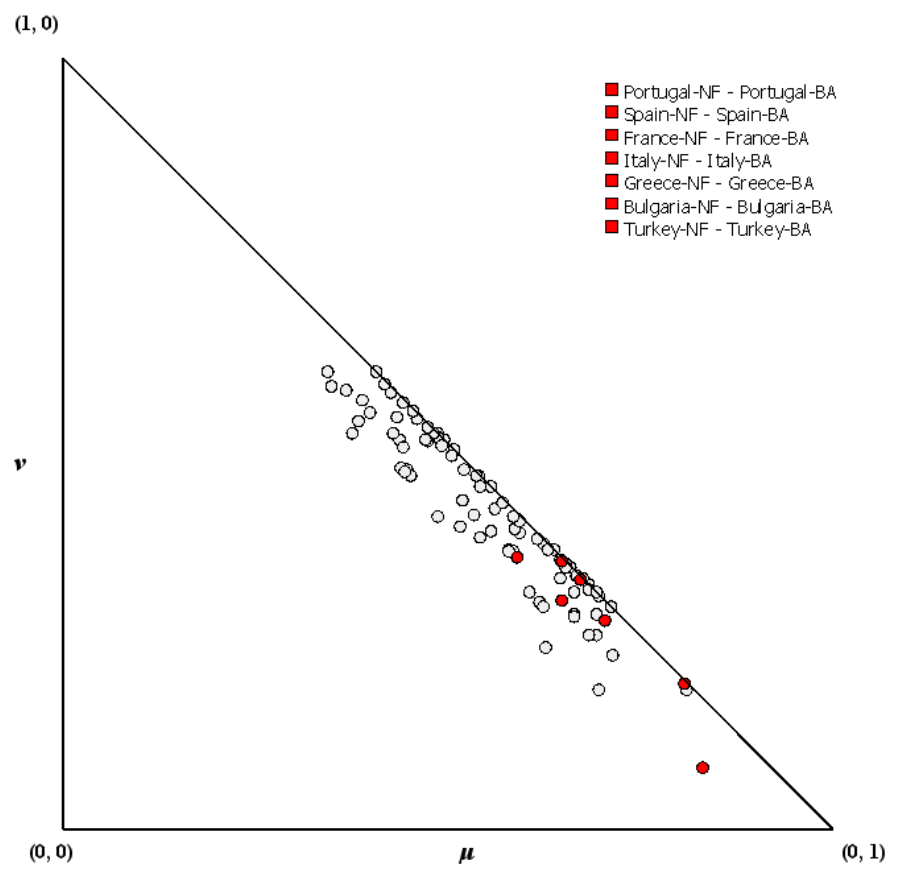

Figure 1. InterCriteria pairs between the numbers of fires and burned areas in the investigated countries (Table 6), as plotted as points (red) on the intuitionistic fuzzy interpretational triangle.

\section{Conclusions and ideas for future work}

The conducted investigation using the intuitionistic fuzzy sets-based novel approach of InterCriteria Analysis on data of the forest fires in the Mediterranean Area in 1990-2017 detects the strongest positive countrywise consonances in the two basic indicators - burned area and number of fires - only between pairs of neighbouring of the investigated countries. Concerning burned area, the strongest consonances are detected in the pairs Italy-Greece $\langle 0.712,0.288\rangle$, Spain-France $\langle 0.698,0.302\rangle$, Greece-Turkey $\langle 0.693,0.307\rangle$, Portugal-Spain $\langle 0.683,0.317\rangle$, while concerning the number of fires the strongest consonance are detected in the pairs Spain-Portugal $\langle 0.810,0.180\rangle$, Turkey-Bulgaria $\langle 0.696,0.180\rangle$, Greece-Italy $\langle 0.714$, $0.225\rangle$, France-Spain $\langle 0.693,0.278\rangle$. On the other hand, when these two indicators are considered in pair, the countries that exhibit highest positive consonances are Bulgaria and Italy. This research can be especially relevant in the context of the new paradigm for panEuropean collaboration in the efforts for fire science research and collaborative prevention of wildfires. A similar, more focused research on the level of regional forest directorates of Bulgaria only, has been already conducted for the period 2009-2018 (see [16]) and 19992018 (see [14]).

Upon available data, the conducted investigation can be performed for the respective countries in Northern Africa, as well as onto all the Mediterranean countries. Another direction of research is feeding the ICA method with same set of data, yet transposed, and to pursue patterns of correlation across the years in the researched period. Furthermore, collecting a variety of other data, reflecting the fire ecology, meteorology, economic losses and damages, etc. - of these countries, can be further informative for the yearly and countrywise trends in the wildfire activity in the Mediterranean Area in support of prediction, prevention, decision making and international cooperation. 


\section{Acknowledgements}

This paper is an extended and improved version of a presentation at the 6th Int. IFS and Contemporary Mathematics Conference, 7-10 June, 2019, Mersin, Turkey. The authors are grateful for the support provided under Grant Ref. No. DN-16-06/2017 "Integrated Approach for Modeling of the Forest Fires Spread" funded by the National Science Fund of Bulgaria.

\section{References}

[1] Atanassov, K., Atanassova, V. \& Gluhchev, G. (2015). InterCriteria Analysis: Ideas and problems, Notes on Intuitionistic Fuzzy Sets, 21 (1), 81-88.

[2] Atanassov, K., Mavrov, D., \& Atanassova, V. (2014). Intercriteria Decision Making: A New Approach for Multicriteria Decision Making, Based on Index Matrices and Intuitionistic Fuzzy Sets. Issues in Intuitionistic Fuzzy Sets and Generalized Nets, 11, $1-8$.

[3] Atanassov, K., Szmidt, E., Kacprzyk, J., \& Atanassova, V. (2017). An approach to a constructive simplification of multiagent multicriteria decision making problems via intercriteria analysis. Comptes rendus de l'Academie bulgare des Sciences, 70 (8), $1147-1156$.

[4] Atanassova, V. (2015). Interpretation in the Intuitionistic Fuzzy Triangle of the Results, Obtained by the InterCriteria Analysis, $16^{\text {th }}$ World Congress of the International Fuzzy Systems Association (IFSA), $9^{\text {th }}$ Conference of the European Society for Fuzzy Logic and Technology (EUSFLAT), 30.06 - 03.07.2015, Gijon, Spain, 1369-1374.

[5] Atanassova, V., \& Roeva, O. (2018). Computational complexity and influence of numerical precision on the results of intercriteria analysis in the decision making process. Notes on Intuitionistic Fuzzy Sets, 24 (3), 53-63.

[6] Doukovska, L., Atanassova, V., Sotirova, E., Vardeva, I., \& Radeva, I. (2019). Defining Consonance Thresholds in InterCriteria Analysis: An Overview. In: Intuitionistic Fuzziness and Other Intelligent Theories and Their Applications, Studies in Computational Intelligence Book series, Volume 757, Springer, Cham, 161-179.

[7] European Forest Fire Information System (EFFIS). Data and Services. Available online: http://effis.jrc.ec.europa.eu/applications/data-and-services/.

[8] Ikonomov, N., Vassilev, P., \& Roeva, O. (2018). ICrAData - Software for InterCriteria Analysis, Int J Bioautomation, 22 (1), 1-10.

[9] Mavrov, D. (2015). Software for InterCriteria Analysis: Implementation of the main algorithm, Notes on Intuitionistic Fuzzy Sets, 21 (2), 77-86.

[10] Mavrov, D., Radeva, I., Atanassov, K., Doukovska, L., \& Kalaykov, I. (2015). InterCriteria Software Design: Graphic Interpretation within the Intuitionistic Fuzzy Triangle, Proceedings of the $5^{\text {th }}$ Int. Symposium on Business Modeling and Software Design, BMSD'2015, 279-283, DOI: 10.5220/0005888202790283. 
[11] Mavrov, D. (2015/2016). Software for InterCriteria analysis: Working with the results. Annual of "Informatics" Section, Union of Scientists in Bulgaria, 8, 37-44.

[12] Roeva, O., Vassilev, P., Angelova, M., Su, J., \& Pencheva, T. (2016). Comparison of Different Algorithms for InterCriteria Relations Calculation. Proc. of IEEE $8^{\text {th }}$ International Conference on Intelligent Systems, 4-6 September 2016, Sofia, Bulgaria, 567-572.

[13] Spano, D., Camia, A., et al. (2014). Recent trends in forest fires in Mediterranean areas and associated changes in fire regimes. In: Moreno J. (Editor) Forest fires under climate, social and economic changes in Europe, the Mediterranean and other fireaffected areas of the world. FUME. Lesson learned and outlook; 2014, 6-7.

[14] Zoteva D., \& Roeva, O. Forest fire analysis based on InterCriteria Analysis, Journal of Universal Mathematics (accepted).

[15] Zoteva, D., \& Roeva, O. (2018). InterCriteria analysis results based on different number of objects, Notes on Intuitionistic Fuzzy Sets, 24 (1), 110-119.

[16] Zoteva, D., Roeva, O., Delkov, A., \& Tsakov, H. (2019). Intercriteria Analysis of Forest Fire Risk, Proceedings of the $4^{\text {th }}$ International Conference on Numerical and Symbolic Computation - Developments and Applications, Porto, 11-12 April 2019, (C)ECOMAS, Portugal, 215-229. 